\title{
COTAS ÉTNICO-RACIAIS COMO POLÍTICA DE REPARO
}

Beatriz Cruvinel. Graduanda em química pelo Instituto Federal Goiano, campus Rio Verde biiacruvinel-@hotmail.com

Eva Luzia das Neves. Docente da educação básica pela Secretaria de educação do estado de Goiás. Licenciada em Hstória pela Universidade Estadual de Goiás; especialização em Formação Sócio Econômica do Brasil pela Universidade Salgado de Oliveira; especialização em História Social e Urbana - evinha-neves@hotmail.com

Odineia Corrêa. Licenciada em Ciências Biológicas pelo Instituto Federal Goiano, campus

Rio Verde - odineiacorrea@ hotmail.com

Samylla Tassia Ferreira de Freitas. Licenciada em Ciências Biológicas pelo Instituto Federal Goiano, campus Rio Verde; mestranda em biodiversidade e conservação pela mesma instituição. Professora de Biologia e Química pela secretaria de educação do estado de Goiás.- Samyllatassia@ hotmail.com

Sandra Mara Santos Lemos de Oliveira. Docente no Instituto Federal Goiano, campus Rio Verde; mestre em Educação para ciências e matemática pelo Instituto Federal de Goiás; doutoranda em Ciências Sociais em Desenvolvimento, Agricultura e Sociedade, pela

Universidade Federal Rural do Rio de Janeiro (UFRRJ)- andra1birol@gmail.com

RESUMO: O presente artigo trata da análise dos resultados de uma pesquisa qualitativa/quantitativa desenvolvida junto aos arquivos da Coordenação de Registros Escolares. Dados quanto à cor/etnia de alunos que ingressaram antes e depois da lei 12.711/2012 começar a ser aplicada na instituição foram coletados a fim de observar o aumento ou diminuição de alunos negros e pardos no curso de agronomia do Instituto Federal Goiano, Campus Rio Verde. Esse levantamento foi realizado com finalidade estatística, como também suscitar a discussão sobre a exclusão racial e a indiferença de parte do universo acadêmico a esse respeito. Para tanto, utilizamos os teóricos Carvalho, Nascimento, Durham, Faria, Gonçalves, Hino, Santos e Kaczmarek no debate sobre cotas; Munanga, Neves, Silva e Barbosa com os conceitos de raça, etnia, cor e participação política; Boris e Prado Júnior para a formação do povo brasileiro. A população negra tem crescido significativamente, entretanto, continuam sendo minoria nos cursos de graduação. Cotas são instrumentos de justiça social para o ingresso no ensino superior e visam diminuir a insondável dívida da sociedade para com os negros. A criação de leis e decretos passou a garantir o ingresso do negro, assim como do pardo e do indígena nas instituições públicas de ensino superior, obedecendo outros critérios, como a procedência de escola pública e renda familiar per capita de no máximo 1,5 salários mínimos, sendo reservada a esse público $50 \%$ das vagas nas instituições federais de ensino. A política de reparo tem mostrado eficácia ao possibilitar o maior acesso de negros à graduação, oportunizando a ascensão social e reduzindo a elitização e o branqueamento visto historicamente no ensino superior. Embora medidas sociais tenham sido tomadas, ainda há muito que avançar e que democratizar quanto ao acesso e permanência, tornando a educação possível a todos, sem distinção.

Palavras-chave: Acesso à universidade. Desigualdade social. Escravidão.

\section{RACIAL AND ETHNIC QUOTAS AS POLICY OF REMEDIATION}

ABSTRACT: This article discusses the results analysis of a quanti-qualitative research developed with the archives of the "Coordenação de Registros Escolares", about color/ethnicity of the students 
who got into school before and after the law 12.711/2012 be applied to the institution, aiming to observe the increase or decrease of black and brown students studying Agronomy at Instituto Federal Goiano, Campus Rio Verde. This mapping was done for statistical purposes, but also to bring the discussion about racial exclusion and apathy of part of academic universe about this topic. Therefore, we used the theorists Carvalho, Nascimento, Durham, Faria, Gonçalves, Hino, Santos and Kaczmarek to discuss quotas, Munanga, Neves, Silva and Barbosa to bring the concepts of race, ethnicity, color and political participation, and Boris and Prado Júnior to talk about formation of Brazilian people. The black population has expressively grown; however, they are still minority in undergraduate courses. Quotas are instruments of social justice to go to college and they aim to decrease the society's unfathomable debt with the negro community. The creation of laws and decrees began to guarantee the place of negro, brown and indigenous people in public institutions of undergraduate and graduate studies, also obeying other criteria, as being students of public school and having a maximum per capita household income of 1,5 minimum wage; and this public has, guaranteed, $50 \%$ of public institutions of education's spots. The compensation policy has shown efficacy to enable greater access for black people to college, creating opportunities for social ascension and reducing elitization and the whiteness historically seen in education. Although social measures have been taken, there is still a lot to improve and to democratize on the access and permanence, to make education possible to everyone, without distinction.

Key-words: Access to university. Social inequalities. Slavery.

\section{INTRODUÇÃO}

A criação da política de cotas nas universidades, objetiva aumentar a participação do negro na vida acadêmica, que devido à segregação, em virtude de diferenças fenotípicas, o exclui do acesso aos direitos civis e serviços públicos. Sendo manifesto o preconceito, principalmente, no que diz respeito ao mercado de trabalho, onde a presença de negros nas posições mais remuneradas e de maior prestígio social é dificultada (DURHAM, 2003).

A Lei 3.524/00 (BRASIL, 2000) é a primeira a instituir a política de cotas para o acesso ao ensino público superior. Surgiu, de acordo (Hino, 2013) como base crítica e defesa, sendo, portanto, a expressão de dois pensamentos vigentes na sociedade: o conservador/neoliberal e o histórico crítico/socialista.

Infelizmente o peso da desigualdade social, interligada ao regime da escravidão, permanece ainda como um problema a ser solucionado. Os negros da África foram arrancados de sua cultura e costumes, trazidos ao Brasil em navios negreiros, sofrendo privação física e moral, sendo, inclusive, marcados com brasa, para colocar o rótulo do proprietário (NASCIMENTO, 2005). Como consequência, o negro teve de lutar para ocupar o seu espaço no país principalmente após a Lei Áurea (BRASIL, 1888).

Partindo desse histórico inegável de escravidão e segregação, Nascimento (2005) afirma que a reserva de cotas para negros tem como finalidade diminuir a insondável dívida da sociedade para com os negros. Para reparar esse débito, Neves (2003) certifica que se faz necessário a ampliação de políticas sociais que incorporem os negros na Universidade, já que estes compõem a maioria do contingente social de pobre e excluído, a fim de desmontar 
gradualmente as desigualdades raciais. Para que isso ocorra, atesta ainda, que os governos precisam promover o desenvolvimento com justiça social. Como é necessário tempo para a consolidação dessas políticas, as raízes da discriminação racial vão perdurando, resultando em uma relação política marcada pela submissão dos negros (NEVES, 2003).

Silva (2006) traz como reflexão o deslocamento do povo negro de seus territórios, o que lhes causou perdas dos sentidos de segurança, pertencimento e esperança. Segundo Seyferth (2002), mesmo que o Brasil tenha uma mestiçagem, prevalece a raça branca, não havendo espaço para os demais grupos étnicos, pois são considerados marginalizados pela sociedade (SILVA, 2006).

Os africanos escravizados eram, de acordo com Boris (1995), considerados juridicamente como coisas e não pessoas, não possuindo, portanto, nenhum direito e a escravidão sendo considerada um processo natural. Aos africanos escravizados não lhes era permitido o direito de aprender a ler, e se lhes era concedido, ocorria com o intuito de incutilos representações negativas de si mesmos. Na época utilizava-se a educação como um modo de despertar no negro o desejo de se tornar branco (SILVA, 2006).

A libertação dos escravos deu uma falsa visão de uma sociedade livre, mas a realidade evidente não era bem assim, os negros foram tirados das senzalas e levados para a cidade tendo de enfrentar uma sociedade carregada de discriminação e preconceito. Tal fato ocorreu devido à abolição da escravatura ter sido um processo em prol do país e sua modernização e não em prol dos negros (KACZMAREK, 2010).

Diante disso, o Brasil tem tomado medidas estratégicas para devolver ao negro o espaço que lhes fora tirado, a partir de políticas de reparação, dentre elas a Lei 10.639 (BRASIL, 2003) "que tornou obrigatório o ensino da história e cultura afro-brasileira e africana em todos os estabelecimentos de ensino da educação básica, tanto da rede pública quando da rede particular" (KACZMAREK, p. 104, 2010), tal Lei estabelece ainda que o calendário escolar contemple o Dia Nacional da Consciência Negra, que é comemorado dia 20 de Novembro. Ainda segundo Kaczmarek (2010), tais medidas foram tomadas com o intuito de diminuir o preconceito que ainda perdura no âmbito escolar, de valorizar e respeitar a cultura e história afro-brasileira e africana.

A Lei 12.711 (BRASIL, 2012) significou um grande avanço na inclusão de estudantes negros, pardos e indígenas na universidade. Tal Lei garante $50 \%$ das vagas de instituições federais de ensino superior para esses estudantes, desde que estes sejam oriundos de famílias com renda per capita inferior a 1,5 salários-mínimos. Esse percentual deve ser 
feito de forma proporcional à quantidade de negros, pardos e indígenas na população, segundo último censo do Instituto Brasileiro de Geografia e Estatística (IBGE). Os debates sobre políticas de reparação continuam e, de acordo com Prado Júnior (1994), das três combinações de sangue possíveis - branco-negro, branco-índio, negro-índio - a primeira prepondera. Frente a esse histórico propõe-se com este texto apresentar um estudo sobre o ingresso de estudantes de agronomia no Instituto Federal Goiano, campus de Rio Verde, antes e após o cumprimento da Lei 12.711.

\section{OBJETIVOS}

A partir de aulas da disciplina de Educação e Cultura Etno-racial, abordando a herança deixada pelo povo africano e sua presença em solo brasileiro, observou-se a exclusão racial e a indiferença de parte do universo acadêmico a esse respeito. Neste sentido, a proposta deste texto é apresentar o resultado de uma pesquisa de dados, discutir e divulgar informações a respeito dos conceitos de raça e etnia, sendo o primeiro um termo já considerado retrógrado.

Como também, enfatizar a importância das cotas étnico-raciais como política de reparo, tendo como base o histórico brasileiro de escravidão, segregação, lutas, movimentos e modificação de legislações em prol da justiça social.

\section{METODOLOGIA}

Os procedimentos metodológicos utilizados na tessitura deste texto percorreram os caminhos embasados na abordagem qualitativa/quantitativa e interpretativa por considerar, a que mais se adequa a este texto, uma vez que se trata de uma investigação bibliográfica com uma temática envolvendo a compreensão pessoal. De acordo com Fonseca (2002), os resultados da pesquisa quantitativa podem ser quantificados e são tomados como se constituíssem um retrato real de toda a população alvo da pesquisa. A pesquisa quantitativa é objetiva e considera que a realidade só pode ser compreendida com base na análise de dados brutos. Esse tipo de pesquisa recorre à linguagem matemática para descrever as causas de um fenômeno.

A utilização conjunta da pesquisa qualitativa e quantitativa permite recolher mais informações do que se poderia conseguir isoladamente (FONSECA, 2002). Esse tipo de pesquisa foi utilizado a fim de observar se houve diferença estatística quanto ao ingresso de estudantes negros e pardos antes e após o vigor da lei 12.711/2012 (BRASIL, 2012). A 
pesquisa foi feita em amostragem; as turmas de agronomia de ingresso em 2012 e 2015 foram tomadas como amostra, que pode ser definida, de acordo com Castanheira (2008), como um subconjunto de elementos retirados da população para obter-se os dados. Após a coleta e análise dos dados foi realizada a inferência estatística, onde ocorre a generalização dos dados obtidos da amostra para toda a população (CASTANHEIRA, 2008).

Isto significa por um lado, que ela compreende atividades de investigação que podem ser denominadas específicas. E, por outro, que todas elas podem ser caracterizadas por traços comuns. Esta é uma ideia fundamental que pode ajudar a ter uma visão mais clara do que pode chegar a realizar um pesquisador que tem por objetivo atingir uma interpretação da realidade do ângulo qualitativo (TRIVINÕS, 2006). Neste sentindo, a representação dos dados parece fundamental para compreender, não de forma dedutiva, mas de forma crítica, o momento da reprodução e da transformação da realidade social. Assim, a abordagem qualitativa/quantitativa leva-nos a um universo de conhecimentos que possibilita compreender as relações existentes entre os dados e as temáticas estudadas.

Como procedimento desta pesquisa, utilizamos como instrumentos de coleta de dados a partir da revisão bibliográfica e da coleta junto a Secretaria do IF Goiano, uma vez que, esta tem como objetivo embasar a pesquisa na análise dos dados. De acordo com Severino (2007), a revisão bibliográfica se realiza a partir do registro disponível, decorrente de pesquisas anteriores, em documentos impressos, como livros, artigos, teses etc. Utiliza-se dados ou de categorias teóricas já trabalhadas por outros pesquisadores e devidamente registrados. O pesquisador trabalha a partir das contribuições dos estudos analíticos constantes dos textos (SEVERINO, 2007). Este tipo de levantamento permite a construção de um aporte teórico que auxiliará na análise dos dados da pesquisa. Daí a necessidade da constituição de um embasamento teórico capaz de promover a reflexão sobre o resultado da pesquisa.

\section{REVISÃO BIBLIOGRÁFICA}

Munanga (2003) traz em sua obra os conceitos de raça, que eram utilizados primordialmente na classificação de espécies animais e vegetais. Posteriormente foi empregada para diferenciar pessoas a partir de suas características físicas e nos séculos XVIXVII passa a atuar em relações sociais, segregando nobreza da plebe. Lamentavelmente, entre XVII-XIX os naturalistas hierarquizaram esses conceitos, relacionando as condições biológicas com as cognitivas e associando o branco como superior ao negro. 
A pseudociência, denominada raciologia ganhou visibilidade nos primeiros anos do século XX, servindo para justificar a exploração racial, escravidão e as atrocidades insondáveis cometidas no triste episódio do nazismo. Diante dessas classificações, Munanga (2003) coloca que a cor da pele é baseada por um critério relativamente artificial, sendo definida pela concentração de melanina, substância que todos possuímos. Considerando, ainda, o avanço da genética, bioquímica e biologia molecular, sabe-se que indivíduos pertencentes a uma mesma raça podem ser geneticamente mais distantes que aqueles pertencentes às raças diferentes, portanto, raça não é uma classificação biológica, trata-se de um conceito que cientificamente nem existe (MUNANGA, 2003).

A partir dessas premissas e chegando mais próximo da realidade brasileira, na plangente história de escravidão no Brasil imperial, Gonçalves e Silva (2007) faz-nos pensar na raiz histórica das diferenças, que não são de características morfológicas, mas sócio históricas, como visto no parágrafo anterior. De acordo com os autores, os africanos escravizados foram privados da alfabetização e de frequentar escolas, apenas alguns filhos de escravos em terras de padres jesuítas eram permitidos o estudo de lições de catecismo, sendo lhes vetado almejar formação média ou superior, entretanto essa instrução de catecismo tinha caráter único repressor. Cursos noturnos, projetados no contexto escravocrata, eram direcionados ao povo livre e liberto, mas em uma grande contradição era vetado em províncias como a de São Pedro do Rio Grande do Sul, onde a presença dos escravos e dos negros livres e libertos. Essas escolas noturnas baseavam-se em mecanismos de exclusão de negros, ainda que livres.

A partir da Lei do Ventre Livre (BRASIL, 1871) os filhos de escravos poderiam receber instrução, desde que os proprietários enviassem-os ao governo mediante indenização, o número de crianças matriculadas chegou a 403.827, entretanto apenas 113 foram entregues ao Estado sendo paga a indenização (GONÇALVES e SILVA, 2007).

Após a promulgação da Lei do Ventre Livre, o número de abandonos na casa dos expostos aumentou significativamente, logo que para os proprietários era mais vantajoso alugar as suas mães como amas de leite (GONÇALVES e SILVA, 2007). Já no início do século XX, as crianças negras estavam afastadas da escola, desempenhando atividades remuneradas precocemente. Em muitos casos, a escolarização ocorreu apenas quando, os homens negros, já haviam atingido a idade adulta (SILVA, 1987). As mulheres negras precisavam trabalhar como empregadas para a manutenção da família, logo que essas, por sua 
habilidade na lida com a casa e cozinha, conseguiam emprego com maior facilidade que os homens (BARBOSA, 1998).

Ao que podemos perceber nas pequenas linhas deste referencial, o negro esteve afastado da escolarização devido ao preconceito, descaso do Estado e à necessidade de trabalhar para a sobrevida. Posteriormente foram criadas associações negras, objetivando combater a discriminação e aumentar a escolarização (GONÇALVES e SILVA, 2007).

Para Carvalho (2002) a composição racial da universidade brasileira é reflexo do contexto escravagista brasileiro e pós-abolicionista. Enquanto ocorreu ascensão de europeus com baixa qualificação, o negro continuou marginalizado. A falta de questionamento a essa problemática, faz com que tal situação fique normatizada, favorecendo o branqueamento das universidades.

\section{RESULTADOS E DISCUSSÃO}

Para a construção dos resultados e discussão, partiremos da interpretação do Instituto de Pesquisa Econômica Aplicada (IPEA, 2008), quando diz que, a população negra tem crescido significativamente, no entanto com relação ao acesso ao ensino superior, não tem havido grandes avanços. A população de negros em 1890 era de 56\%, tendo caído em 1940 para 35,8\%, se mantendo estável durante duas décadas, havendo aumento da densidade tanto da população negra quanto branca. No censo de 1960, negros e pardos correspondiam a $37,5 \%$ da população brasileira. A partir da década de 70 a densidade populacional decresceu e houve aumento da taxa de natalidade de negros e diminuição da taxa de natalidade de brancos. Em 1976 a população de brancos era maior que a de negros. Em 2006 a população de negros já era praticamente equivalente.

De acordo com o último censo do IBGE, realizado em 2010, negros e pardos juntos correspondem a $50,7 \%$ da população brasileira, portanto, mesmo que eventualmente tratados como minorias, são maioria na população e por isso merecem mais atenção e inclusão.

O índice de analfabetismo (IBGE, 2010) entre a população com mais de 15 anos de idade, era mais evidente entre a população negra e parda (Gráfico I), especialmente no Nordeste, onde a população negra é mais densa. Há discrepância também entre o grau de ensino frequentado por negros, pardos e brancos (Gráfico II), onde o percentual de negros no ensino superior é de $12,8 \%$, de pardos é de $13,4 \%$, contra $31,1 \%$ de brancos frequentando o 
ensino superior, o que afirma a real necessidade da política cotista, para democratizar o ensino superior.

Gráfico I: Taxa de analfabetismo das pessoas de 15 anos ou mais de idade, por cor ou raça, segundo as Grandes Regiões.

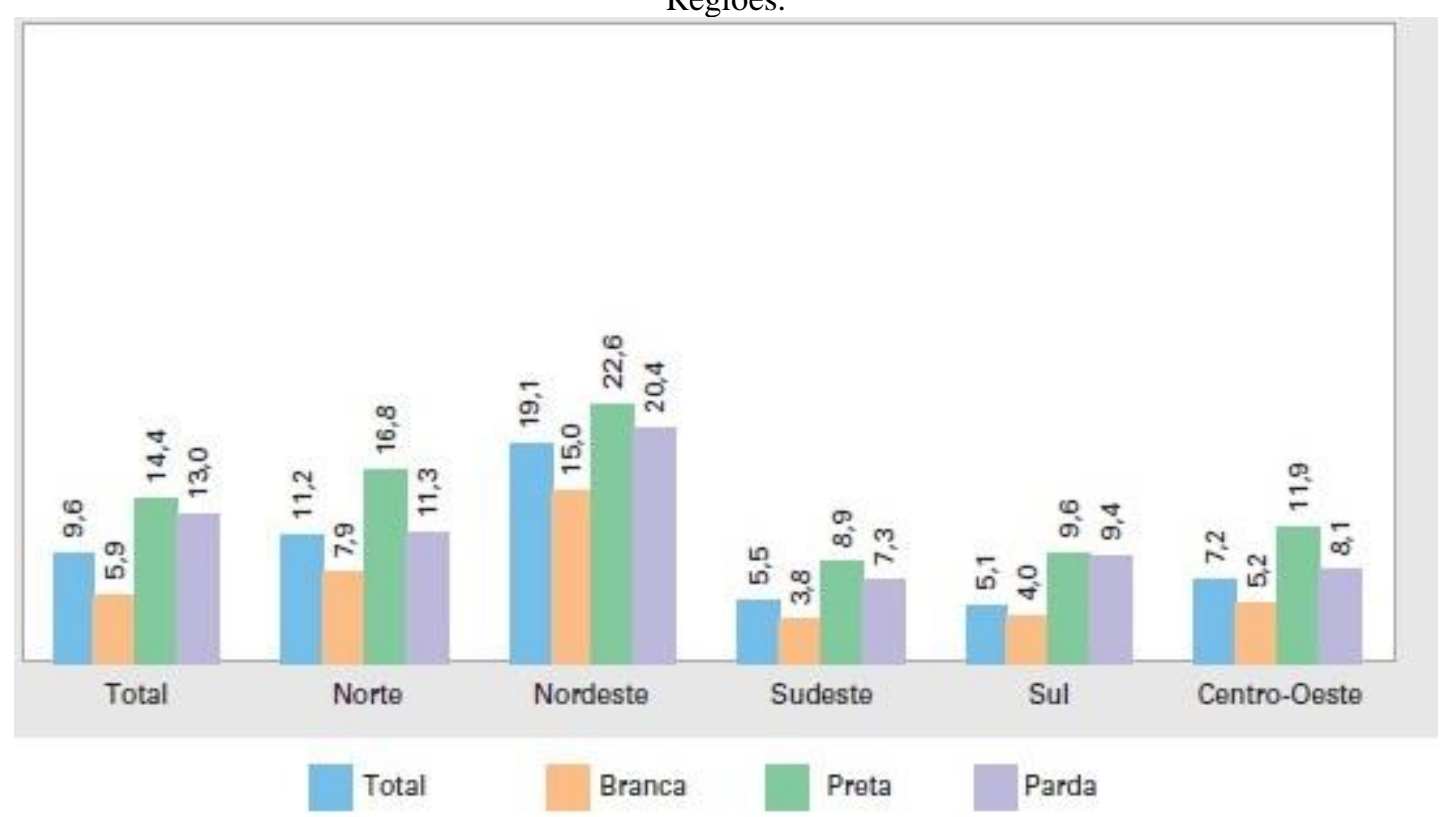

Fonte: IBGE, Censo demográfico, 2010.

Gráfico II: Distribuição das pessoas de 15 anos a 24 anos de idade que frequentavam escola por cor ou raça, segundo o nível do ensino frequentado.

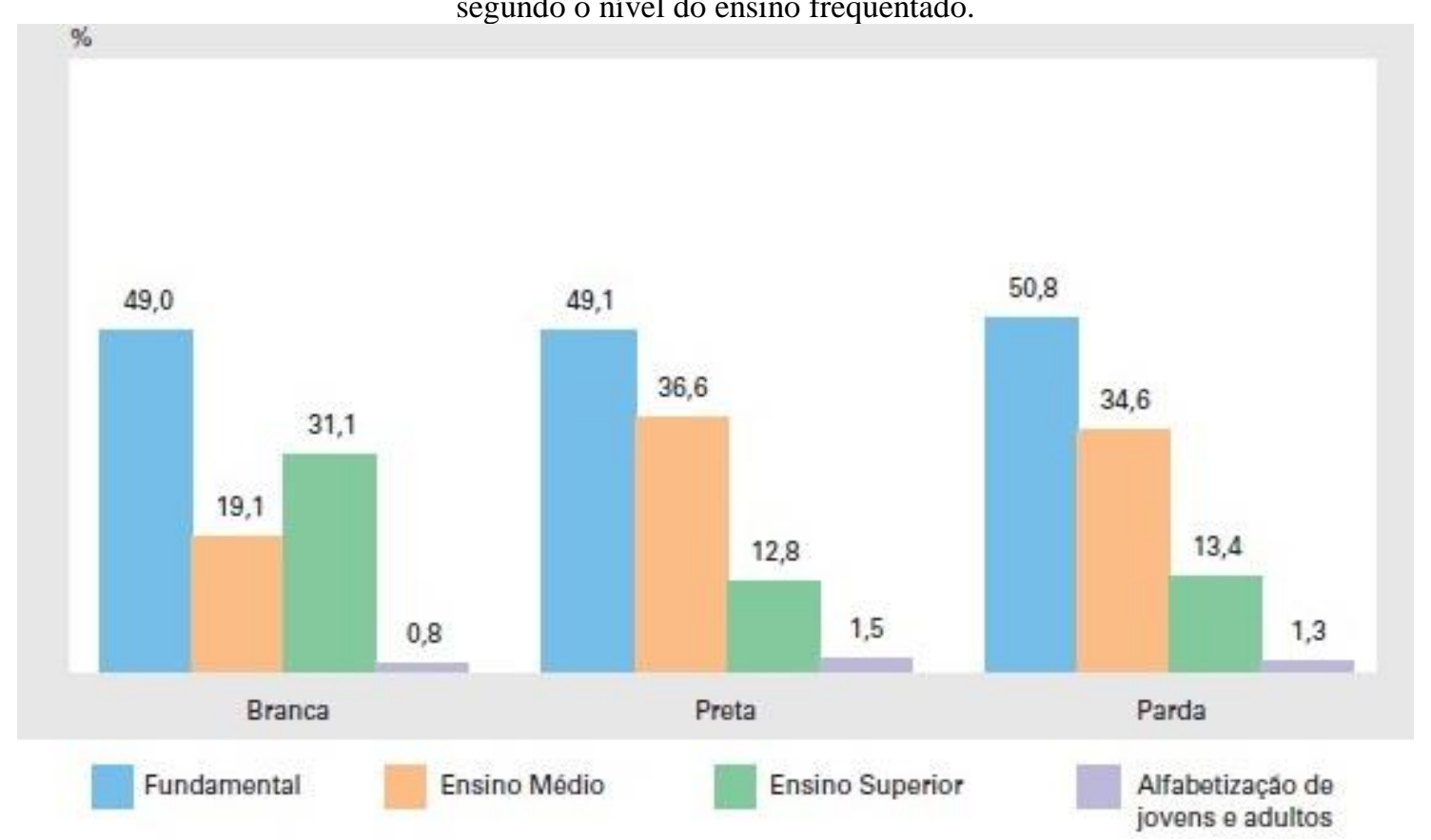

Fonte: IBGE, Censo demográfico, 2010.

Foram coletados dados quanto à cor/etnia de alunos que ingressaram antes e depois da lei 12.711/2012 começar a ser aplicada na instituição, a fim de observar o aumento 
ou diminuição de alunos negros e pardos no curso de agronomia do Instituto Federal Goiano Campus Rio Verde. Esse levantamento foi realizado junto à Coordenação de Registros Escolares, com finalidade estatística.

Os dados apresentados no texto e as observações feitas ao longo do semestre revelam a quantidade mínima de negros e afrodescendentes que frequentam as aulas no Instituto Federal Goiano - Campus Rio Verde. Esta realidade passava despercebida, uma vez que não fazia parte da realidade discente questionar a pouca existência de negros no ensino superior. $\mathrm{O}$ debate sobre políticas de reparação foi tomando corpo à medida que se estudava $\mathrm{e}$ percebia-se que o número de colegas e professores negros era menor. Segundo Santos (2012) a introdução de cotas permitiu o início da democratização do conhecimento, tornando as universidades menos elitistas e mais capacitadas para lidar com diferenças.

Quando observado o quantitativo de estudantes de agronomia que ingressaram no Instituto Federal Goiano de Rio Verde, no ano de 2012 (Gráfico III), antes da lei 12.711/2012 entrar em vigor, notou-se a baixa quantidade de alunos negros ingressantes e quantidade equivalente entre pardos e brancos.

Gráfico III: Percentual de estudantes brancos, negros, pardos e outros ingressantes no curso de agronomia do Instituto Federal Goiano em 2013, por sexo.

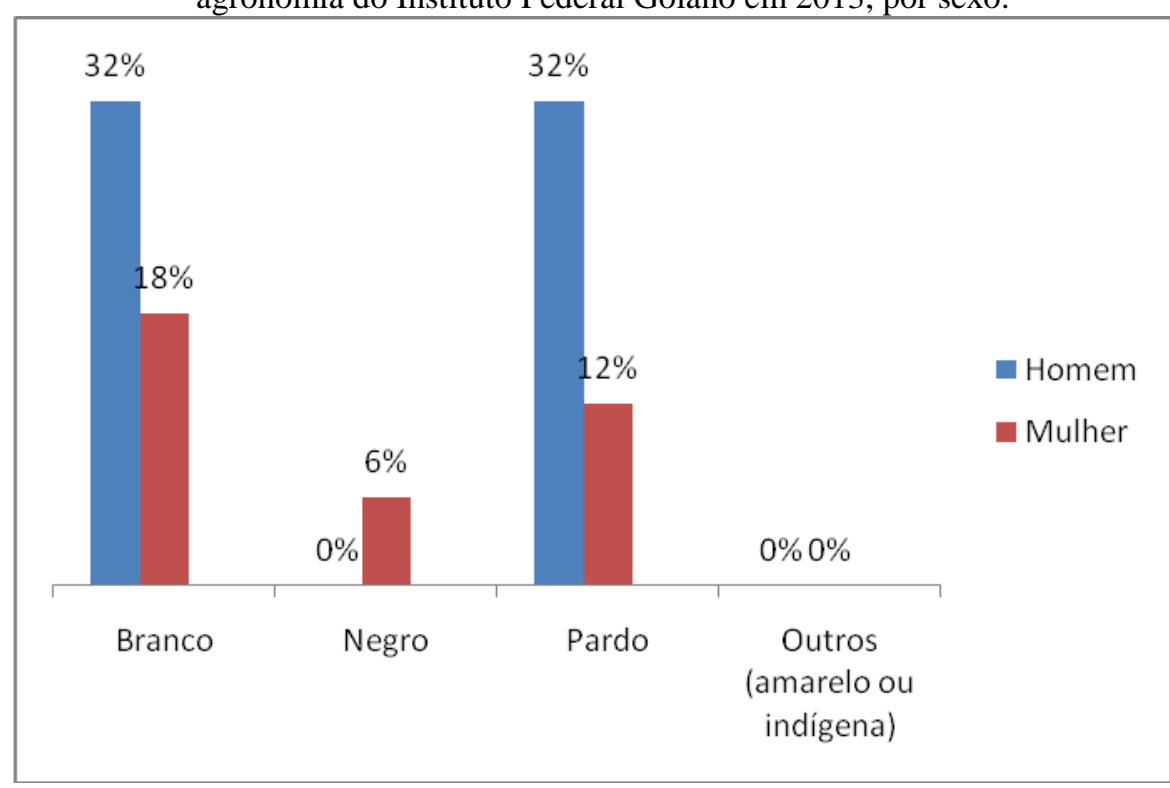

Fonte: do autor.

Apesar de a população negra ser predominante no Brasil, ainda há desigualdade social. De acordo com o último censo do IBGE (2010), a população de pardos e negros somada correspondia a $50,7 \%$, tendo subido desde o censo de 2000 , enquanto a população de brancos decresceu. Representaria maior justiça social a elevação da presença de estudantes 
negros nos bancos das universidades. A Lei 12.711/2012 (BRASIL, 2012) garante, em seu artigo terceiro, o percentual de vagas em instituições federais de ensino superior preenchidas por autodeclarados pretos, pardos e indígenas.

No processo seletivo de 2013 essa Lei começou a ser cumprida na instituição, garantindo maior homogeneidade no ingresso dos estudantes. Houve aumento de $6 \%$ para 14,2\% na matrícula de estudantes negros, considerando total de homens e mulheres, no curso de agronomia, sendo o primeiro resultado obtido em 2012 (gráfico III), antes da seleção por cotas e o segundo em 2015 (gráfico IV). Quanto ao número de estudantes pardos, a representação passou de 44\% (gráfico III) para 57,1\% (gráfico IV).

Dos estudantes autodeclarados pardos 68,8\% ingressaram no curso através da política de cotas. Os estudantes autodeclarados negros que tiveram seus ingressos garantidos pela Lei 12.711/2012 corresponderam a 50\%. É importante considerar também a presença de brancos que ingressaram por cota garantida a pessoas com renda per capita inferior a 1,5 salários-mínimos, que foi $37,5 \%$ do total de alunos brancos matriculados.

Gráfico IV: Percentual de estudantes brancos, negros, pardos e outros ingressantes no curso de agronomia do Instituto Federal Goiano em 2015, por sexo.

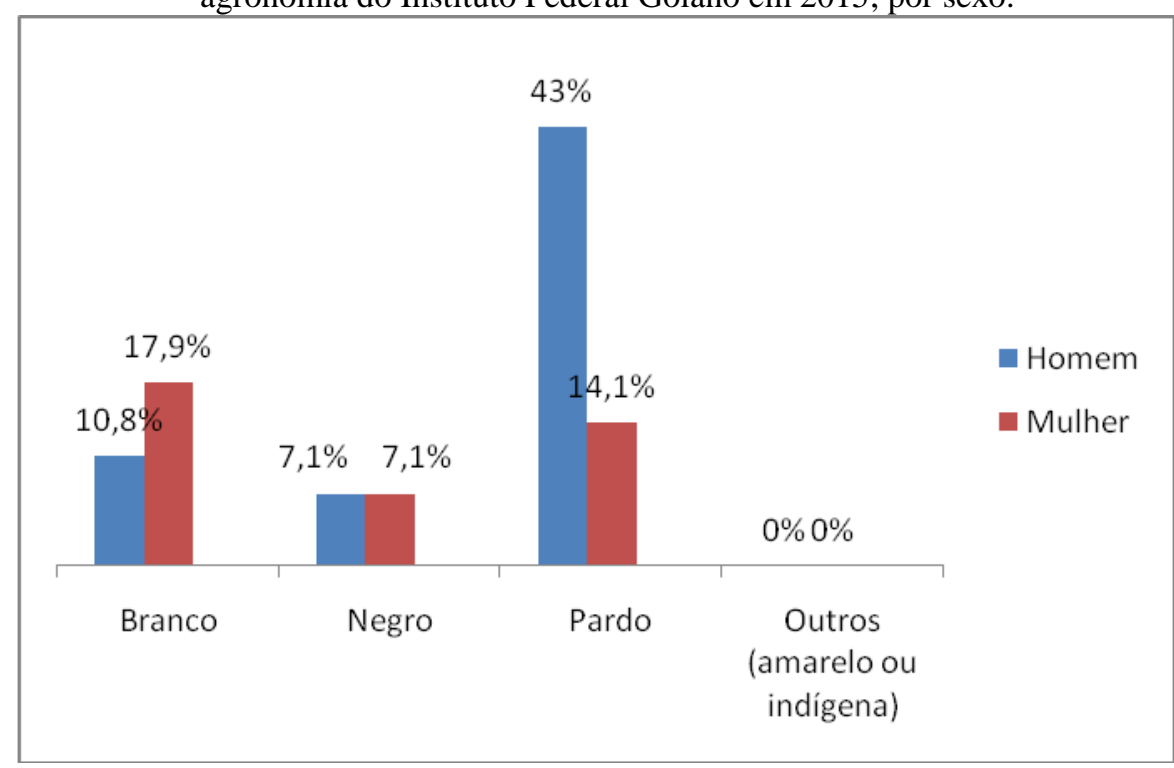

Fonte: do autor.

Vale ressaltar que mesmo existindo programas e políticas de reparação, ainda contamos com um número muito alto de negros fora da escola e esta realidade só será modificada quando formos capazes de nos olharmos como humanos, uma vez que a humanidade não permite tratamento diferenciado entre os seus. 
Faria (2015) afirma que a universidade pública é muito importante na promoção da educação, entretanto essa educação tem historicamente formado elites. Para democratizar o ensino superior são necessárias políticas públicas aplicadas a todos, sem distinção, mas que tratem de forma diferenciada aqueles em situação desigual. De acordo com a autora, a Lei 12.711/2012, apesar de questionada, é constitucional e articula as cotas raciais também com as sociais e econômicas. Salienta, ainda, o dever do Estado em tornar à educação acessível a todos.

\section{CONSIDERAÇÕES FINAIS}

A proposta desta pesquisa foi investigar a partir das discussões nas aulas da disciplina de Educação e Cultura Etno-racial, a herança deixada pelo povo africano e sua presença em solo brasileiro, a exclusão racial e a indiferença de parte do universo acadêmico; como também, o reflexo da política de inclusão, tomando como base os estudantes do curso de Agronomia no IF Goiano campus Rio Verde.

As considerações que trazemos coadunam com as informações apresentadas, e ficou claramente demonstrados por meio de todos os argumentos e dados expostos no corpo deste trabalho. A população de brasileiros negros encontra-se em nítida desvantagem em relação aos seus co-nacionais no que tange a instrução formal. O que consequentemente os coloca como maioria entre os mais pobres e limita seriamente suas possibilidades de ascensão social. Esta situação é consequência da formação histórica de nosso país, que durante séculos sustentou-se em uma estrutura social e econômica baseada no escravismo étnico, ou, colocando de forma mais clara, na exploração da mão-de-obra de escravos africanos e seus descendentes.

Essa realidade, logicamente, impôs aos negros, durante o período escravocrata uma completa exclusão social, sendo-lhes vetado, de modo geral, o acesso à educação, que, mesmo quando lhes era permitida funcionava muito mais como instrumento de manipulação.

$\mathrm{O}$ advento de leis que restringiram ou findaram a escravidão, pouco modificou a realidade dos negros, que não experimentaram melhoras em sua situação socioeconômica, ao contrário de outros grupos raciais que conseguiram ascender socialmente.

Esta história marcada por injustiça social ressoa ainda nos dias atuais, tanto que, embora a população de negros e pardos tenha apresentado um forte crescimento demográfico nos últimos 30 anos, ao ponto de alavancar sua representação em relação à população total no 
Brasil, o nível de qualificação e acesso a educação, inclusive a universidade, não acompanhou este aumento.

Em outras palavras, o crescimento da população negra em pouco alterou sua dura realidade social. $\mathrm{O}$ aumento de população não trouxe consigo a alteração do quadro de desvantagem social, tendo em vista que a população cresceu, mas não se tornou mais qualificada, nem tampouco teve oportunidades para tanto.

É inegável, portanto, que a herança do passado escravista está ainda fortemente presente em nossa história, como se a marca de propriedade que o senhor deixava em seus cativos fosse transmitida aos seus descendentes e ainda pudesse ser vista, de modo a manterlhes em estado de segregação.

Diante desta triste realidade, o Estado deve assumir uma postura mais ativa, objetivando a diminuição deste abismo de oportunidades, que insiste em separar os negros e pardos do restante da população e nada mais eficaz para o alcance desta obrigação histórica do que propiciar qualificação à população negra do Brasil.

O sistema de cotas atende esse objetivo e, embora para setores mais conservadores pareça fomentar a injustiça, por beneficiar um cidadão em detrimento a outro em virtude da cor de sua pele, ele na verdade, atenua a imensa injustiça e desigualdade a qual os negros estão ainda submetidos, proporcionando-lhes a chance de cursar uma universidade, oportunidade esta que talvez jamais tivessem, e consequentemente, ascender socialmente.

Não se deve esquecer que, em regra, os negros ainda estão longe das melhores escolas, das melhores universidades, dos melhores empregos, dos melhores bairros, longe de verem garantidos seus direitos à educação e dignidade e o sistema de cotas embora não seja por si só suficiente, é sem dúvida um importante passo nessa direção.

\section{REFERÊNCIAS BIBLIOGRÁFICAS}

BARBOSA, M. Frente Negra: Depoimentos. São Paulo: Quilombo Hoje. 1998.

BORIS, F. História do Brasil. São Paulo: Edição da Universidade de São Paulo, 1995.

BRASIL. Lei 2.040, de 28 de setembro de 1871.

BRASIL. Lei 3.353, de 13 de maio de 1888 .

BRASIL. Lei 3.524, de 28 de dezembro de 2000.

BRASIL. Lei 12.711, de 29 de agosto de 2012. 
BRASIL, Portal. Censo 2010 mostra as características da população brasileira. Disponível em WWW.brasil.gov.brleducação. Publicado em 02\07/2012. Acesso em 16 de junho de 2015.

CARVAlHO, J. J. Uma Proposta de Cotas Para Estudantes Negros na Universidade de Brasília. CEPE, 2002.

CASTANHEIRA, N. P. Estatística aplicada a todos níveis. Editora Ibpex, 2008.

DURHAM, E. R. Desigualdade Educacional e Cotas Para Negros Nas Universidades. Novos Estudos CEBRAP. n. 66. São Paulo, 2003.

FARIA, I. P. O Ingresso Em Instituições Federais De Ensino Superior: Um Estudo Interdisciplinar Das Cotas Para Discentes E Docentes. UFB. Salvador, 2015.

FONSECA, J. J. S. Metodologia da pesquisa científica. Fortaleza: UEC, 2002. Apostila.

GONÇALVES, L. A. O.; SILVA, P. B. G. E. Movimento Negro e Educação. Educação como Exercício de diversidade. MEC. Anped, 2007.

HINO, B.A. B; LIMA, J.P. Sistemas de Cotas nas Universidades Públicas, revista científica sensus: pedagogia, v.03, n.02. Londrina, 2013.

IBGE. Censo demográfico 2010. Características Gerais da População, Religião e Pessoas com deficiência. Rio de Janeiro, 2012.

IPEA. Desigualdades raciais, Racismo e Políticas Públicas: 120 anos após a abolição. Comunicado à Presidência: n.04. Brasília, 2008.

KACZMAREK, M. D. V.; SANDINI, S. P. Mudanças Curriculares Após a Lei 10.639: Uma Possível Alforria da História e cultura Afro-Brasileira e Africana. VOOS Revista Polidisciplinar Eletrônica da Faculdade Guairacá: v. 02, Ed. 01. 2010.

MUNANGA, K. Uma abordagem conceitual das noções de Raça, Racismo, Identidade e Etnia. Palestra proferida no $3^{\circ}$ Seminário Nacional Relações Raciais e Educação - PENESB - Rio de Janeiro, 2003.

NASCIMENTO, M. A. Reserva de Cotas para Negros. Direito Federal, v. 79, p. 135-139, 2005.

NEVES, G. CotasPara Negros na Estratégia de Inclusão Social na Universidade.Revista de Educação Popular: n.02. Uberlândia, 2003.

PRADO JÚNIOR, C. História econômica do Brasil. 41ª Ed. São Paulo: Brasiliense, 1994.

PRADO JÚNIOR, C. Formação do Brasil Contemporâneo: colônia. 23a Ed. São Paulo: Brasiliense, 1997.

SANTOS, J. C. Cotas nas universidades: análises dos processos de decisão. Organizador. ISBN 978-Salvador: CEAO, 2012 
SEVERINO, A. J. Metodologia do trabalho científico. 23. ed. rev. e atualizada. São Paulo: Cortez, 2007.

SILVA, P. B. G. Histórias de operários negros. Porto alegre: Nova Dimensão. 1987.

SILVA, P. B. G. Aprender, ensinar e relações étnico-raciais no Brasil. Educação: n.3, p. 489506, 2007.

TRIVIÑOS, A. S. A dialética materialista e a prática social. Movimento, v. 12, n. 2, p. 121, 2006. 